\title{
Potential of Rubus Ulmifolius Schott Supplementation in the Attenuation of Sucrose-Induced Hyperglycemia, Dyslipidemia and Liver Oxidative Damage in Rats
}

\author{
Madani $Z^{1}$, Majdoub $\mathbf{H}^{2}$, Righi K ${ }^{3}$, Malaisse $\mathbf{W J}^{4}$, Ait-Yahia $\mathrm{D}^{5^{*}}$ \\ ${ }^{1}$ University of Sidi Said, Faculty of Natural Sciences and Life, Department of Biology, Mascara, Algeria \\ ${ }^{2}$ University Abu Baker Belkaid, Faculty of Natural Sciences and Life, Department of Biology, Tlemcen, Algeria \\ ${ }^{3}$ University Mustapha Stambouli Research Laboratory Biological Systems and Geomatics, Mascara, Algeria \\ ${ }^{4}$ Department of Biochemistry, Free University of Brussels. Route de Lennik 808, B-1070 Brussels, Belgium \\ ${ }^{5}$ University of Oran1 BENBELLA Ahmed, BP 1524 El M’Naouer Es Senia, Oran, Algeria
}

"Corresponding author: Pr Ait-Yahia Dalila, University of Oran1 BENBELLA Ahmed, BP 1524 El M'Naouer Es Senia, Department of Biology, 31000, Oran, Algeria, Tel: 00213779082043; E-mail: aityahiad@yahoo.fr

\begin{abstract}
Metabolic syndrome is associated with several disorders, including hypertension, diabetes, hyperlipidemia as well as cardiovascular diseases and stroke. The purpose of the present study was to investigate the preventive effect of Rubus ulmifolius Schott extract (E) on hyperglycemia, hyperlipidemia and liver oxidative stress in rats fed a high-sucrose diet.

Male Wistar rats $(\mathrm{n}=21)$ weighing $115 \pm 3 \mathrm{~g}$ were used in this experiment. For induction of MS, fourteen rats were given free access to $60 \%$ sucrose in drinking water and seven rats received water for 3 weeks. After this induction phase, rats were assigned to three equal-weight groups as follows:

1) C: rats were kept on standard pellet diet.

2) HSD: rats were kept on high-sucrose diet containing $60 \%$ sucrose for 3 weeks.

3) HSD + E: rats were kept on HSD and orally administered $300 \mathrm{mg} / \mathrm{kg}$ of extract by stomach tube once daily for a period of 3 weeks.

Rats exposed to a sucrose-rich diet exhibited similar body weight despite lower food intake when comparing to control rats. Increased plasma glucose, $\mathrm{HbA1C}$, triglycerides, total cholesterol (TC), VLDL-C, LDL-C, TC-HDL-C/HDL-C, total protein, albumin, fibrinogen, urea, uric acid, creatinine, ALT, AST, decreased HDL-C and impaired tolerance to glucose was reported in HS-fed rats. We also observed high TBARS and low SOD, CAT and GSH-Px activities in liver. Supplementation of HS diet with Rubus ulmifolius Schott extract at a $300 \mathrm{mg} / \mathrm{kg}$ dose improved glucose tolerance, hyperglycemia, HbA1c, dyslipidemia, liver and renal abnormalities and liver oxidative stress when compared to HSD rats.

Taken as a whole, these results support the favorable effect of Rubus ulmifolius Schott extract in sucrose-induced metabolic syndrome on such variables as hyperglycemia, glucose tolerance, lipid metabolism, and liver oxidative damage, suggesting that Rubus ulmifolius Schott could be beneficial to counteract deleterious dietary sucrose in an animal metabolic syndrome model.
\end{abstract}

Received date: September 27, 2016

Accepted date: November 07, 2016

Published date: November 16, 2016

Citation: Ait-Yahia, D., et al. Potential of Rubus Ulmifolius Schott Supplementation in the Attenuation of Sucrose-Induced Hyperglycemia, Dyslipidemia and Liver Oxidative Damage in Rats. (2016) J Diab Obes 3(2): $67-72$.

DOI: $10.15436 / 2376-0494.16 .1141$

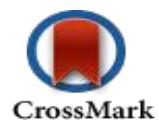

Keywords: Sucrose-rich diet; Rats; Rubus ulmifolius Schott; Glucose tolerance; Oxidative stress; Lipids; Plasma; Lipoproteins; Liver. 


\section{Introduction}

The prevalence of metabolic syndrome and its interrelated complications has increased worldwide due to the modern lifestyle and an increased consumption of high-sugar diets ${ }^{[1]}$. Insulin resistance is an important predisposing condition to type 2 diabetes mellitus. Type 2 diabetes $^{[2]}$ is a major cause of morbidity and mortality worldwide, and a predisposing condition for high blood pressure, some dyslipidemias, and coronary heart disease $^{[3]}$. There are plausible mechanisms and research evidence that supports the suggestion that consumption of excess sugar promotes the development of cardiovascular disease (CVD) and type 2 diabetes (T2DM) both directly and indirectly ${ }^{[4]}$.

Plants are important sources for the preparation of natural remedies, food additives, and other ingredients, as they contain many biologically active compounds as polyphenols, vitamins (A, B group, C, E), terpenes, organic acids, and other very important phytochemicals ${ }^{[5,6]}$. For this reason, plant material and herbal preparations have been widely used for hundreds of years all over the world ${ }^{[7]}$ : they have provided a complete storehouse of remedies to cure acute and chronic diseases.

Rubus ulmifolius Schott (Rosaceae), known as wild blackberry, is a perennial shrub found in wild and cultivated habitats in Europe, Asia and North Africa. Natural products and related structures are increasingly becoming essential sources of new pharmaceuticals, because of the immense variety of functionally relevant secondary metabolites.

In traditional herbal medicine, Rubus ulmifolius Schott have been used for different therapeutic purposes ${ }^{[8]}$, antiviral ${ }^{[9]}$, anti-inflammatory activity, anti-haemorrhoids and diarrhoea activity ${ }^{[10,11]}$, antiprofilative cancer cells ${ }^{[12]}$ and also for its beneficial effects ${ }^{[13]}$. It forms the majority of hedgerows, the vast majority of bushes agricultural areas and abandoned fallow.

No studies evaluating the effects of Rubus ulmifolius Schott extract on metabolic syndrome have been reported so far. Therefore, this study was aimed to determine the potential effect of Rubus ulmifolius Schott extract on hyperglycemia, glucose tolerance, dyslipidemia and liver oxidative stress markers of rats fed a HS diet.

\section{Materials and Methods}

Plant material. Rubus ulmifolius Schott (Rosaceae) were collected from OCHBA, Tlemcen, Algeria around the end of May. The plant was authenticated by Professor Righi at the Laboratory of Research on Biological systems and Geomatics, University of Mascara. The samples were rinsed thoroughly under running tap water and then the clean samples were then dried at room temperature until they were completely dried before grinding them into powder form. Then, the aerial part of the plant was recovered and stored in a dry place prior to use.

\section{Preparation of plant extracts}

Dry plant materials were ground into a fine powder using a homogenizer. Each $20 \mathrm{~g}$ of powdered aerial parts was submitted to maceration in $200 \mathrm{ml}$ of distilled water at room temperature for $24 \mathrm{~h}$. The maceration was then filtered using a 300 -mesh filter, and the filtrate was concentrated at $50^{\circ} \mathrm{C}$ for 24 $\mathrm{h}$. The residue obtained was the crude aqueous extract.

\section{Animals, induction of metabolic syndrome, and diets}

Twenty one male Wistar rats obtained from Iffa-Credo, (L'Arbresle, France) and weighing $115 \pm 3 \mathrm{~g}$ at the beginning of the experiment were used for the study. The rats were kept in a laboratory animal house with an alternate exposure to $12 \mathrm{~h}$ light: dark cycle (07:00 - 19:00). Throughout the experiment, temperature of the animal room was maintained at $24^{\circ} \mathrm{C}$ and humidity at $60 \%$. For induction of MS, fourteen rats were free access to $60 \%$ sucrose in drinking water for 21 days, while others received water. After this induction phase, rats were assigned to three equalweight groups as follows:

1) $C$ : rats were kept on standard pellet diet.

2) HSD: rats were kept on HSD containing 60\% sucrose for 3 weeks.

3) HSD + E: rats with HSD were orally administered a dose of $300 \mathrm{mg} / \mathrm{kg}$ of Rubus ulmifolius Schott by stomach tube once daily for a period of 3 weeks.

Diets and tap water were freely available for 3 weeks. The animals were weighed weekly. Blood glucose was measured weekly. The animal experiment was conducted in accordance with the guide for the care and use of laboratory animals published by the Council of European Communities, (1987) ${ }^{[14]}$. Food intake and body weight were monitored weekly.

\section{Glucose tolerance test}

After twenty nine day of experiment, rats were fasted overnight before the intraperitoneal glucose tolerance test (IPGTT). A $2.0 \mathrm{~g}$ D-glucose $/ \mathrm{kg}$ body weight was intraperitoneally injected in awake and fasted rats. Blood samples were sequentially collected via the tail vein before time $0,30,60$, and 120 min after injection.

\section{Blood and tissue collection}

At the end of the feeding period, after overnight fasting, blood was withdrawn via the abdominal aorta under chloral anesthesia ( $60 \mathrm{mg} / \mathrm{kg}$ body weight) in heparinized tubes. Plasma obtained after low speed centrifugation $\left(4000 \times \mathrm{g}, 20 \mathrm{~min}, 4^{\circ} \mathrm{C}\right)$ was stored at $-70^{\circ} \mathrm{C}$ for biochemical analysis. Liver tissue was excised, weighed and immediately frozen at $-70^{\circ} \mathrm{C}$ until needed for analysis.

\section{Plasma glucose, HbA1C, lipid profile and transaminase ac- tivity}

Glycated haemoglobin (HbA1C) was determined by micro column enzymatic method (Biocon, Diagnostik, GmbH, Burbach, Germany). Plasma glucose, total cholesterol, triglycerides, LDL-C, HDL-C, urea, uric acid, creatinine, aspartate aminotransferase (AST), alanine aminotransferase (ALT), total protein and albumin were estimated using commercially available standard assay kits (Spinreact, Girona, Spain). Plasma urea, creatinine and albumin levels were determined using commercial kits purchased from Spinreact, (Girona, Spain). Circulating fibrinogen concentrations were assayed by using an assay kit (Cypress Diagnostics, Langdorp, Belgium). HDL-C was achieved by precipitation of plasma by adding precipitating reagent (phosphotungstic acid and dextran sulfate-magnesium chloride) after centrifugation at 3,000 rpm, the supernatant was estimated for HDL-C by using cholesterol reagent (cholesterol esterase and cholesterol oxidase) and measured colorimetri- 
cally at a wavelength of $500 \mathrm{~nm}$. Very low density lipoprotein (VLDL-C) was calculated by dividing TG/5. Atherogenic index (AI) was calculated by the equation: $\mathrm{AI}=(\mathrm{TC}-\mathrm{HDL}-\mathrm{C}) / \mathrm{HDL}-\mathrm{C}$.

\section{Liver lipid peroxidation assay}

Lipid peroxidation levels in the liver tissues were evaluated using the thiobarbituric acid reactive substances (TBARS) assay as described by the method of Quintanilha et al. ${ }^{[15]}$. For TBARS measurement, tissue homogenate was deprotenized with $10 \%$ trichloroacetic acid (TCA) and the precipitate was treated with thiobarbituric acid (TBA) at $90^{\circ} \mathrm{C}$ for $1 \mathrm{~h}$. The absorbance was measured at $532 \mathrm{~nm}$ using a spectrophotometer (Cary 50; Varian, Palo Alto, CA, USA). The concentration was expressed as $\mu \mathrm{mol} / \mathrm{g}$ tissue.

\section{Liver antioxidant enzyme activities}

Liver homogenates prepared on ice in a ratio of $1 \mathrm{~g}$ wet tissue to $9 \mathrm{ml} 150 \mathrm{mmol} / \mathrm{l} \mathrm{KCL}$ using a Polytron homogenizer, were used for superoxide dismutase (SOD, EC 1.15.1.1), glutathione peroxidase (GSH-Px, EC 1.11.1.9) and catalase (CAT, EC, 1.11.1.6) determinations. SOD activity was determined using an SOD assay kit according to the manufacturer's protocol (Cayman Chemical kit, USA). Briefly, the method uses xanthine and xanthine oxidase to generate superoxide radicals, which react with 2-(4-iodophenyl)-3-(4-nitrophenyl)-5-phenyltetrazolium chloride to form a formazan dye. The SOD activity was measured by the degree of inhibition of the reaction at $440 \mathrm{~nm}$ using a spectrophotometer. The results were expressed in $\mathrm{U} / \mathrm{mg}$ of protein. CAT activity was measured at $240 \mathrm{~nm}$ according to the method of Aebi ${ }^{[16]}$ and the results were expressed in $\mathrm{nmol} / \mathrm{mg}$ of protein. Tissue GPH-Px activity was measured by enzymatic method at $340 \mathrm{~nm}$ using Cayman Chemical kit, (USA). The data were expressed in $\mathrm{nmol} / \mathrm{min} / \mathrm{mg}$ of protein.

\section{Statistical analysis}

Data are presented as mean \pm SD of seven rats per group. Statistical analysis was performed using the Statistica 6 (Statsoft, Tulsa, OK). The statistical significance of differences between groups was analyzed using one-way analysis of variance (ANOVA). In all analyses, a difference of $\mathrm{P} \leq 0.05$ was considered significant. ${ }^{\mathrm{a}}<0.05$, HSD and HSD-E groups versus $\mathrm{C}$ group. ${ }^{\mathrm{b}} \mathrm{P}<0.05$, HSD-E group versus HSD group.

\section{Results}

\section{Food intake and body and liver weights}

Table I lists body and liver masses and food and water intakes for control, diet induced MS and experimental Rubus ulmifolius Schott extract groups. After the 6-week feeding period, although high sucrose ingestion decreased food (1.98-fold) and water (1.22-fold) consumption, the average of body and liver weights did not differ when compared to $\mathrm{C}$ group. Twenty one days of Rubus ulmifolius Schott extract treatment significantly increased food intake $(80 \%)$ without modifying body and liver weights and water intake compared with the HSD group.

\section{Glucose tolerance test}

The profile of plasma D-glucose concentrations during the IGPTT in the three groups of rats is depicted in Figure 1. HSD treatment caused a significant increase in plasma D-glucose levels at any time points during the IGPTT study as compared to their controls. Administration of Rubus ulmifolius Schott extract to HSD treated rats revealed a significant decrease in plasma D-glucose when comparing to HSD.

Table I: Body and liver weights, food intake and adiposity in control and experimental groups ${ }^{1}$.

\begin{tabular}{|l|l|l|l|}
\hline & $\mathrm{C}$ & HSD & HSD-E \\
\hline Initial body weight $(\mathrm{g})$ & $115 \pm 3$ & $115 \pm 3$ & $115 \pm 3$ \\
\hline Final body weight $(\mathrm{g})$ & $240 \pm 17$ & $235 \pm 4.50$ & $229.57 \pm 12$ \\
\hline Food intake $(\mathrm{g} / \mathrm{d} / \mathrm{rat})$ & $15.91 \pm 3.11$ & $8.02 \pm 3.21^{\mathrm{a}}$ & $14.41 \pm 2.98^{\mathrm{b}}$ \\
\hline Water intake $(\mathrm{ml} / \mathrm{d} / \mathrm{rat})$ & $15.00 \pm 2.32$ & $12.30 \pm 2.04^{\mathrm{a}}$ & $12.12 \pm 1.96^{\mathrm{a}}$ \\
\hline Liver weight $(\mathrm{g})$ & $7.54 \pm 0.24$ & $8.22 \pm 0.82$ & $7.67 \pm 0.60$ \\
\hline Index of adiposity & $2.94 \pm 0.17$ & $3.79 \pm 0.12^{\mathrm{a}}$ & $2.98 \pm 0.14^{\mathrm{b}}$ \\
\hline
\end{tabular}

${ }^{1}$ Data are mean \pm SD of seven rats per group. ${ }^{a} \mathrm{P}<0.05$, HSD and HSD-E groups versus $\mathrm{C}$ group. ${ }^{\mathrm{b}} \mathrm{P}<0.05$, HSD-E group versus HSD group.

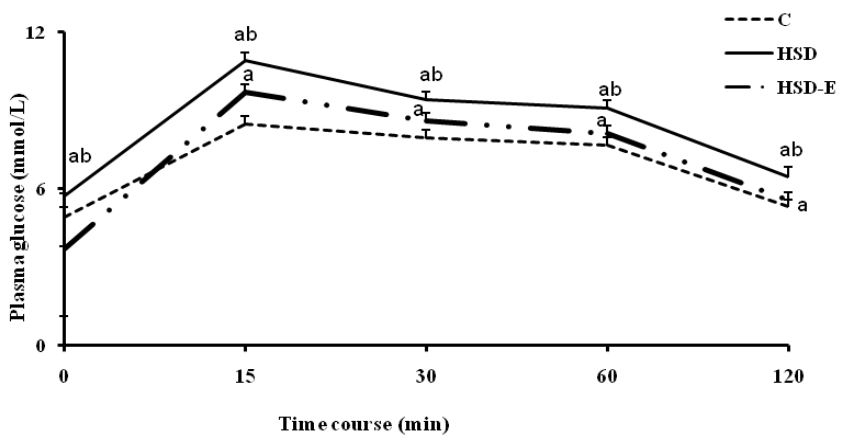

Figure 1: Plasma glucose response to IPGTT in rats fed control diet (C) and high sucrose diet (HSD) with or without Rubus ulmifolius Schott extract $(E)$ for 42 days. Mean values $( \pm S D)$ refer to 7 rats in each group. ${ }^{*} \mathrm{P}<0.05$, HSD and HSD-E groups versus $\mathrm{C}$ group. ${ }^{\mathrm{b}} \mathrm{P}<0.05$, HSD-E group versus HSD group.

\section{Plasma glucose and lipid profile}

Plasma lipid profile, glucose and HbA1c, are shown in Table II. The high sucrose diet considerably elevated plasma total cholesterol (1.17-fold), VLDL-C (2.93-fold), LDL-C (1.56-fold), TC-HDL-C/HDL-C (5.48-fold), triglycerides (2.97fold), glucose (1.27-fold) and HbA1c (1.43-fold), and decreased HDL-C (2.02-fold) when compared to the control diet. After 21 days of treatment with the extract at a dose of $300 \mathrm{mg} / \mathrm{kg} \mathrm{BW}$, there was a significant decrease of glucose (1.8-fold), HbAlc (1.74-fold), total cholesterol (1.91-fold), triglycerides (4.46fold), VLDL-C (4.44-fold), LDL-C (1.65-fold), TC-HDL-C/ HDL-C (2.90-fold) but elevation of HDL-C (1.66-fold), which was compared to HSD. Moreover, as compared to C group, HSD-E group reduced plasma glucose, HbA1C, TG, VLDL-C, HDL-C and increased TC-HDL-C/HDL-C. Administration of Rubus ulmifolius Schott to HSD rats were sufficient to return plasma TC and LDL-C levels to those observed in C-fed animals.

Table II: Plasma metabolic data in control and experimental groups ${ }^{1}$.

\begin{tabular}{|l|l|l|l|}
\hline & C & HSD & HSD-E \\
\hline
\end{tabular}




\begin{tabular}{|l|l|l|l|}
\hline \hline Glucose (mmo/L) & $5.44 \pm 0.01$ & $6.93 \pm 0.08^{\mathrm{a}}$ & $3.85 \pm 0.03^{\mathrm{ab}}$ \\
\hline HbA1C (\%) & $5.45 \pm 0.03$ & $7.80 \pm 0.03^{\mathrm{a}}$ & $4.47 \pm 0.06^{\mathrm{ab}}$ \\
\hline TG (g/L) & $0.75 \pm 0.20$ & $2.23 \pm 0.76^{\mathrm{a}}$ & $0.50 \pm 0.17^{\mathrm{ab}}$ \\
\hline TC (g/L) & $1.24 \pm 0.16$ & $1.46 \pm 0.83^{\mathrm{a}}$ & $1.30 \pm 0.26^{\mathrm{b}}$ \\
\hline VLDL-C (g/L) & $0.15 \pm 0.04$ & $0.44 \pm 0.15^{\mathrm{a}}$ & $0.10 \pm 0.03^{\mathrm{ab}}$ \\
\hline LDL-C (g/L) & $0.37 \pm 0.16$ & $0.58 \pm 0.12^{\mathrm{a}}$ & $0.35 \pm 0.11^{\mathrm{b}}$ \\
\hline HDL-C (g/L) & $0.85 \pm 0.18$ & $0.42 \pm 0.15^{\mathrm{a}}$ & $0.70 \pm 0.35^{\mathrm{ab}}$ \\
\hline TC-HDL-C/HDL-C & $0.45 \pm 0.11$ & $2.47 \pm 0.81^{\mathrm{a}}$ & $0.85 \pm 0.25^{\mathrm{ab}}$ \\
\hline
\end{tabular}

${ }^{1}$ Data are mean $\pm \mathrm{SD}$ of seven rats per group. ${ }^{\mathrm{a}} \mathrm{P}<0.05$, HSD and HSD-E groups versus $\mathrm{C}$ group. ${ }^{\mathrm{b}} \mathrm{P}<0.05$, HSD-E group versus HSD group.

\section{Plasma total proteins, albumin and fibrinogen}

he HSD-fed rats displayed significant increase in plasma total proteins (1.75-fold), albumin (1.12-fold) and fibrinogen (1.37-fold) when compared to C rats (Table III). Administration of Rubus ulmifolius Schott extract to HSD treated rats revealed a significant decrease in plasma total proteins (1.66-fold) and fibrinogen (1.27-fold) as compared to HSD. In addition, the inclusion of extract to HD rats restored albumin and fibrinogen levels similar to those of $\mathrm{C}$ rats.

Table III: Plasma total proteins, albumin and fibrinogen in control and experimental groups ${ }^{1}$.

\begin{tabular}{|l|l|l|l|}
\hline & C & HSD & HSD-E \\
\hline Total proteins (g/l) & $51.50 \pm 2.00$ & $90.30 \pm 3.00^{\mathrm{a}}$ & $54.30 \pm 2.00^{\mathrm{ab}}$ \\
\hline Albumin (g/l) & $26.70 \pm 2.50$ & $30.10 \pm 1.70^{\mathrm{a}}$ & $28.90 \pm 1.80$ \\
\hline Fibrinogen (g/l) & $1.34 \pm 0.14$ & $1.84 \pm 0.13^{\mathrm{a}}$ & $1.44 \pm 0.12^{\mathrm{b}}$ \\
\hline
\end{tabular}

${ }^{1}$ Data are mean \pm SD of seven rats per group. ${ }^{\text {aP }}<0.05$, HSD and HSD-E groups versus $\mathrm{C}$ group. ${ }^{\mathrm{b}} \mathrm{P}<0.05$, HSD-E group versus HSD group.

Table IV: Plasma urea, uric acid, creatinine, ALT and AST activities in control and experimental groups ${ }^{1}$.

\begin{tabular}{|c|c|c|c|}
\hline & C & HSD & HSD-E \\
\hline Urea (mg/dl) & $0.31 \pm 0.03$ & $2.19 \pm 0.07^{\mathrm{a}}$ & $0.40 \pm 0.20^{\mathrm{ab}}$ \\
\hline Uric acid (mg/dl) & $3.50 \pm 1.27$ & $6.95 \pm 1.62^{\mathrm{a}}$ & $4.00 \pm 0.32^{\mathrm{b}}$ \\
\hline Creatinine (mg/dl) & $0.55 \pm 0.02$ & $1.32 \pm 0.10^{\mathrm{a}}$ & $0.42 \pm 0.03^{\mathrm{ab}}$ \\
\hline ALT (U/l) & $28.05 \pm 1.03$ & $44.54 \pm 2.12^{\mathrm{a}}$ & $31.43 \pm 0.10^{\mathrm{ab}}$ \\
\hline $\operatorname{AST}(\mathrm{U} / \mathrm{I})$ & $25.33 \pm 0.07$ & $39.54 \pm 1.07^{\mathrm{a}}$ & $25.50 \pm 0.05^{\mathrm{b}}$ \\
\hline
\end{tabular}

${ }^{1}$ Data are mean $\pm \mathrm{SD}$ of seven rats per group. ${ }^{\mathrm{a}} \mathrm{P}<0.05$, HSD and HSD-E groups versus $\mathrm{C}$ group. ${ }^{\mathrm{b}} \mathrm{P}<0.05$, HSD-E group versus HSD group.

\section{Plasma urea, uric acid, creatinine, AST and ALT levels}

HSD treatment caused a significant increase in plasma urea (7.06-fold), uric acid (1.98), creatinine (2.4-fold), ALT (1.58-fold) and AST (1.56-fold) when compared to C diet as shown in Table IV. Exposition to Rubus ulmifolius Schott treatment significantly ameliorated the increase of plasma urea, uric acid, creatinine, AST and ALT levels. Moreover, Rubus ulmifolius Schott returns circulating uric acid and AST to near control values in HS-fed animals.

\section{Hepatic levels of oxidative stress biomarkers}

Exposition to HS diet led to an increase of TBARS with respect to their controls (Table V). Moreover, the high-sucrose diet drastically altered the hepatic antioxidant biomarkers such

as, SOD (57\%), CAT (70\%) and GSH-Px (67\%) activity than in the control group. Upon Rubus ulmifolius Schott supplementation for 21 days at a dose of $300 \mathrm{mg} / \mathrm{kg}$ rats, the concentrations of liver TBARS were significantly reduced by $27 \%$ and the levels all of these antioxidant enzymes (SOD 141\%, CAT 247\%, and GSH-Px 191\%) were to a greater extent in HSD rats. Treatment of HSD with Rubus ulmifolius Schott normalized TBARS, SOD, CAT and GSH-Px when compared to control diet.

Table V: Liver TBARS, SOD, CAT and GSH-Px activities in C, HSD and HSD + E treated groups ${ }^{1}$.

\begin{tabular}{|c|c|c|c|}
\hline & $\mathrm{C}$ & HSD & HSD-E \\
\hline $\begin{array}{l}\text { TBARS }(\mathrm{nmol} / \mathrm{mg} \\
\text { protein) }\end{array}$ & $0.98 \pm 0.04$ & $1.21 \pm 0.06^{\mathrm{a}}$ & $0.88 \pm 0.04^{\mathrm{b}}$ \\
\hline SOD (U/mg protein) & $55.76 \pm 0.32$ & $23.98 \pm 0.45^{\mathrm{a}}$ & $57.87 \pm 0.23^{\mathrm{b}}$ \\
\hline $\begin{array}{l}\text { CAT (nmol/mg } \\
\text { protein) }\end{array}$ & $1.93 \pm 0.03$ & $0.57 \pm 0.20^{\mathrm{a}}$ & $1.98 \pm 0.02^{\mathrm{b}}$ \\
\hline $\begin{array}{l}\text { GSH-Px }(\mu \mathrm{mol} / \mathrm{min} / \\
\text { mg protein) }\end{array}$ & $1.03 \pm 0.10$ & $0.34 \pm 0.03^{\mathrm{a}}$ & $0.99 \pm 0.10^{\mathrm{b}}$ \\
\hline
\end{tabular}

${ }^{1}$ Data are mean \pm SD of seven rats per group. ${ }^{\mathrm{a}} \mathrm{P}<0.05$, HSD and HSD-E groups versus $\mathrm{C}$ group. ${ }^{\mathrm{b}} \mathrm{P}<0.05$, HSD-E group versus HSD group.

\section{Discussion}

The present study showed the non significant change in the mean body weights of the three groups, in spite of changes in food intake. This result is in agreement with several studies that found that feeding with high-sucrose diets did not increase the body weight of rats over the long term ${ }^{[17-19]}$. Rats on HSD ate less but gained more body fat, suggesting that this diet may favor the development of fat accumulation independent of excessive energy intake. Sucrose intake is characterized by a severe elevated adiposity and impaired glucose function ${ }^{[20-22]}$. Upon Rubus ulmifolius Schott supplementation for 21 days at a dose of $300 \mathrm{mg} / \mathrm{kg}$ rats, the index of adiposity was significantly reduced despite of high food feeding.

In the present current, the HSD impaired glucose tolerance as evidenced by the IPGTT and elevated plasma glucose and $\mathrm{HbA} 1 \mathrm{C}$ even though minimal impact on body weight was detected as compared to $\mathrm{C}$ diet and this was likely due to reduced insulin suppression of glucose production and increased capacity of gluconeogenesis ${ }^{[23,24]}$. Our results are supported by other studies on rat obesity models that showed a tissue specific sequence in the development of diet-induced insulin resistance ${ }^{[17,18]}$. Rats fed a $40 \%$ sucrose diet developed accelerated features of metabolic syndrome with up regulation of fructose-dependent transporter Glut 5 and fructokinase ${ }^{[17]}$. Oral administration of the extract at a dose of $300 \mathrm{mg} / \mathrm{kg}$ BW improved plasma glucose, HbA1C, glucose tolerance in HSD rats. Together, our results show the pharmaceutical potential of Rubus ulmifolius Schott as an herb-derived remedy improving the glucose abnormalities.

We also reported that the HS diet resulted in dyslipidemic changes as indicated by increased plasma levels of TG, TC, VLDL-C, LDL-C, TC-HDL-C/HDL-C ratio and a lower level of HDL-C compared with the control diet. Similar results were observed $^{[25]}$. The HS-diet has a very high lipogenic capacity, arising predominantly from the dramatic increase in glycolytic flux caused by the bypassing by fructose of a rate-determining enzymatic reaction (Phosphofructokinase) and fructose-6-phos- 
phate-stimulated recruitment of glucokinase to the cytoplasm ${ }^{[26]}$. Much of this flux is directed into lipogenesis in the rat, presumably because of a supply of glycolytic intermediates that are in excess of what can be metabolized by the liver through nonlipogenic pathways. The hypertriglyceridemia produced by high sucrose diet may be due to increased secretion of TG, which decreased the catabolism of the rats ${ }^{[27]}$. Exposure of HS rats to Rubus ulmifolius Schott significantly improved HS diet-mediated dyslipidemia by increasing the level of cardioprotective HDL-C and decreased the levels of TC, VLDL-C, LDL-C, TC$\mathrm{HDL}-\mathrm{C} / \mathrm{HDL}-\mathrm{C}$ ratio and TG at a dose of $300 \mathrm{mg} / \mathrm{kg} \mathrm{BW}$. The increased HDL-C levels in HSD-E administered rats indicates the possibility of increased transport of peripheral tissue cholesterol to the liver, decreasing the blood cholesterol level and thus acting as a protective factor, suggesting that these effects were independent of alterations in body and liver weights but to low adiposity. Moreover, the decreases induced by Rubus ulmifolius Schott were sufficient to return TG and LDL-C levels to those observed in C-fed animals. It could be reasonably inferred that improved dyslipidemia by Rubus ulmifolius Schott extract could be a result of polyphenols which contribute to the hypolipidemic activity by increasing the cholesterol metabolism and by modulating the enzymes involved in cholesterol metabolism, such as HMG-CoA reductase, lecithin cholesterolacyl transferase, cholesterol $7 \alpha$-hydroxylase and acyl-CoA:cholesterol acyltransferase. Moreover, it has been reported that flavonoids intake decreased LDL-C and increased HDL-C that may hasten removal of cholesterol from peripheral tissue to liver for catabolism and excretion ${ }^{[28]}$. Our results also revealed that increase in sucrose consumption exerts a significant difference on plasma fibrinogen, albumin and total proteins. Similar results were reported $^{[29,30]}$. Fibrinogen has been implicated in the etiology of cardiovascular disease ${ }^{[31]}$ by promoting fibrin formation and it is a major contributor to plasma viscosity, a condition that increases fibrinogen level as in case of sucrose feeding may affect cardiovascular risk factors. Rats treated with Rubus ulmifolius Schott extract reduced significantly total proteins and fibrinogen levels as compared to those untreated.

The concentrations of urea, uric acid and creatinine were greater in plasma of HSD-fed rats, suggesting renal diseases or renal damage associated with metabolic syndrome, while a significant decrease in these parameters was observed in animals of the treated group. Uric acid has been shown to enter cells via specific transporters such as URAT-1 where it can induce proinflammatory and pro-oxidative effects ${ }^{[32,33]}$.

In our study, Rubus ulmifolius Schott extract improved liver function by decreasing the plasma ALT and AST levels in HSD rats and these enzymes have been restored to the normal value, indicating the curative action of Rubus ulmifolius Schott extract. Hepatospecific enzymes are activated when hepatocellular damage gives rise to abnormalities of liver function. AST and ALT activities in plasma are generally accepted as an index of liver damage, and ALT is used as a highly liver-specific enzyme $^{[34]}$.

Hyperglycemia in conjuncture with hyperlipidemia increased oxidative stress. The present study showed that animals fed HS diet suffer from oxidative stress as indicated by the significant increment of lipid peroxidation (TBARS) in liver, which is associated to depletion in cellular enzymatic antioxidant potential, such as SOD, CAT and GSH-Px activities and to high circulating glucose, which enhances free radical production from glucose autoxidation. The inclusion of Rubus ulmifolius Schott significantly reduced lipid peroxidation and enhanced the antioxidant enzymatic defense as compared to HSD rats, which suggests that the tested extract was protective and curative against liver toxicity. The antioxidant activity of Rubus ulmifolius Schott extract could be attributed to the presence of polyphenols $(71.03 \%)$ such as catechins $(50.06 \%)$, benzoic acids $(10.56 \%)$, cinnamic acid $(6.88 \%)$, flavonols $(3.80 \%)$, followed by organic acids $(27.34 \%)$ and vitamins $(1.36 \%)^{[35]}$, which act as scavengers of various oxidizing species i.e., super oxide anion $(\mathrm{O} \bullet-)$, hydroxyl radical or peroxy radicals and as quenchers of singlet oxygen.

Taken as a whole, these results indicated the potential of Rubus ulmifolius Schott in the attenuation of hyperglycemia, glucose intolerance, hyperlipidemia, hepatotoxicity and improved oxidative damage, suggesting that this herbal could be beneficial to counteract deleterious dietary sucrose in an animal metabolic syndrome model.

Conflict of Interests: The authors declare no conflict of interests.

\section{References}

1. Misra, A., Khurana, L. Obesity and the metabolic syndrome in developing countries. (2008) J Clin Endocrinol Metab 93(11): S9-S30.

2. Korenblat, K.M., Fabbrini, E., Mohammed, B.S., et al. Liver, muscle and adipose tissue insulin action is directly related to intrahepatic triglyceride content in obese subjects. (2008) Gastroenterology 134(A): 1369-375.

3. Weber, M.B., Twombly, J.G., Venkat Narayan, K.M., et al. Lifestyle interventions and the prevention and treatment of Type 2 diabetes. (2010) Am J Lifestyle Med 4(6): 468-480.

4. Stanhope, K.L. Sugar consumption, metabolic disease and obesity: The state of the controversy. (2016) Crit Rev Clin Lab Sci 53(1): 52-67. 5. Ramawat, K., Dass, S., Mathur, M. The chemical diversity of bioactive molecules and therapeutic potential of medicinal plants. (2009) In Herbal Drugs: Ethnomedicine to Modern Medicine 7-32.

6. Verpoorte, R. Medicinal plants: A renewable resource for novel leads and drugs. In Herbal Drugs: Ethnomedicine to Modern Medicine. (2009) Springer, Berlin Heidelberg, Germany: 1-5.

7. Pal, S.K., Shukla, Y. Herbal medicine: Current status and the future. (2003) Asian Pacific J Cancer Prev 4(4): 281-288.

8. Leonti, M., Casu, L., Sanna, F., et al. A comparison of medicinal plant use in Sardinia and Sicily-de Materia Medica revisited? (2009) J Ethnopharmacol 121(2): 255-267.

9. Panizzi, L., Caponi, C., Catalano, S., et al. In vitro antimicrobial activity of extracts and isolated constituents of Rubus ulmifolius. (2002) Ethnopharmacol 79(2): 165-168.

10. Gudej, J., Tomczyk, M. Determination of flavonoids, tannins and ellagic acid in leaves from Rubus L. species. (2004) Arch Pharm Res 27(11): 1114-1119.

11. Zuniga-Hansen, M.E., Poirrier, P., Soto, C. Effect of solvent type on Rubus ulmifolius (Blackberry)'s phenolic antioxidant recovery. (2010) J Biotechnol 150: S1-S576.

12. Hannum, S.M. Potential impact of strawberries on human health: a review of the science. (2004) Crit Rev Food Sci Nutr 44(1): 1-17.

13. Guarrera, P.M. Traditional phytotherapy in central Italy (Marche, Abruzzo, and Latium). (2005) Fitoterapia 76(1): 1-25.

14. Council of European Communities. Council instructions about the protection of living animals used in scientific investigations. (1987) Official J L358 of 18-12-1986. 
15. Quintanilha, A.T., Packer, L., Szyszio, D.J.M., et al. Membrane effects of vitamin E deficiency bioenergetic and surface charge density studies of skeletal muscle and liver mitochondria. (1982) Ann NY Acad Sci 393: 32-47.

16. Aebi H: Catalase. In: Methods of Enzymatic Analysis. Bergmeyer HU (ed) 2nd edition (1974) Verlag Chemie Weinheim 673-684.

17. Roncal-Jimenez, C.A., Lanaspa, M.A., Rivard, C.J., et al. Sucrose induces fatty liver and pancreatic inflammation in male Breeder rats independent of excess energy intake. (2011) Metabolism 60(9): 12591270 .

18. Cao, L., Liu, X., Cao, H., et al. Modified high-sucrose diet-induced abdominally obese and normal-weight rats developed high plasma free Fatty Acid and insulin resistance. (2012) Oxid Med Cell Longev 2016: $1-9$.

19. Angelova, P., Boyadjiev, N. A review on the models of obesity and metabolic syndrome in rats. (2013) Thrakia J Sci 11: 5-12.

20. Sheludiakova, A., Rooney, K., Boakes, R.A. Metabolic and behavioural effects of sucrose and fructose/glucose drinks in the rat. (2012) Eur J Nutr 51(4): 445-54.

21. Kendig, M.D., Rooney, K.B., Corbit, L.H., et al. Persisting adiposity following chronic consumption of $10 \%$ sucrose solution: Strain differences and behavioural effects. (2014) Phys Behav 130: 54-65.

22. Kendig, M.D., Lin, C.S., Beilharz, J.E., et al. Maltodextrin can produce similar metabolic and cognitive effects to those of sucrose in the rat. (2014) Appetite 77: 1-12.

23. Bizeau, M.E., Short, C., Thresher, J.S., et al. Increased pyruvate flux capacities account for diet-induced increases in gluconeogenesis in vitro. (2001) Am J Physiol Regul Integr Comp Physiol 281(2): 427-433. 24. Commerford, S.R., Ferniza, J.B., Bizeau, M.E., et al. Diets enriched in sucrose or fat increase gluconeogenesis and G-6-Pase but not basal glucose production in rats. (2002) Am J Physiol Endrocrinol Metab 283: E545-E555.

25. Huang, W., Dedousis, N., O'Doherty, R.M. Hepatic steatosis and plasma dyslipidemia induced by a high-sucrose diet are corrected by an acute leptin infusion. (2007) J Applied Physiol 102(6): 2260-2265.

26. Bizeau, M.E., Pagliassotti, M.J. Hepatic adaptations to sucrose and fructose. (2005) Metabolism 54(9): 1189-1201.

27. Kanazawa, M., Xue, C.Y., Kageyama, H., et al. Effects of a high-su- crose diet on body weight, plasma triglycerides, and stress tolerance. (2003) Nutr Rev 61(5): S27-S33.

28. McCrindle, B.W., Ose, L., Marais, A.D. Efficacy and safety of atorvastatin in children and adolescents with familial hypercholesterolemia or severe hyperlipidemia: a multicenter, randomized, placebo-controlled trial. (2003) J Pediatr 143(1): 74-80.

29. Salau, B.A., Ketiku, A.O., Adebayo, O.L., et al. Modulation of cardiovascular risk factors (heamotological heamorrheological parameters) caused by sucrose diet. (2013) Am J Biomchem Mol Biol 3(1): 119-126.

30. Aguilera, A.A., Díaz, G.H., Barcelata, M.L., et al. Effects of fish oil on hypertension, plasma lipids, and tumor necrosis factor-alpha in rats with sucrose-induced metabolic syndrome. (2004) J Nutr Biochem 15(6): 350-357.

31. Allen, J.D., Wilson, J.B., Tulley, R.T., et al. Influence of age and normal plasma fibrinogen levels on flow-mediated dilation in healthy adults. (2000) Am J Cardiol 86: 703-705.

32. Price, K.L., Sautin, Y.Y., Long, D.A., et al. Human vascular smooth muscle cells express a urate transporter. (2006) J Am Soc Nephrol 17(7): 1791-1795.

33. Sautin, Y.Y., Nakagawa, T., Zharikov, S., et al. Adverse effects of the classic antioxidant uric acid in adipocytes: NADPH oxidase-mediated oxidative/nitrosative stress. (2007) Am J Physiol Cell Physiol 293(2): C584-596.

34. Dhanasekaran, M., Baskar, A.A., Ignacimuthu, S., et al. (2009) Chemopreventive potential of Epoxy clerodane diterpene from Tinospora cordifolia against diethylnitrosamine-induced hepatocellular carcinoma. (2009) Invest New Drugs 27(4): 347-355.

35. Donno, D., Mellano, M.G., Cerutti, A.K. et al. Biomolecules and Natural Medicine Preparations: Analysis of New Sources of Bioactive Compounds from Ribes and Rubus spp. Buds. (2016) Pharmaceuticals (Basel) 9(1).
Ommega Online Publishers

Journal Title: Journal of Diabetes and Obesity (JDO)

Journal Short Name: J diabetes Obes
Journal ISSN: 2356-0494

E-mail: diabetes@ommegaonline.com

Website: www.ommegaonline.org 